
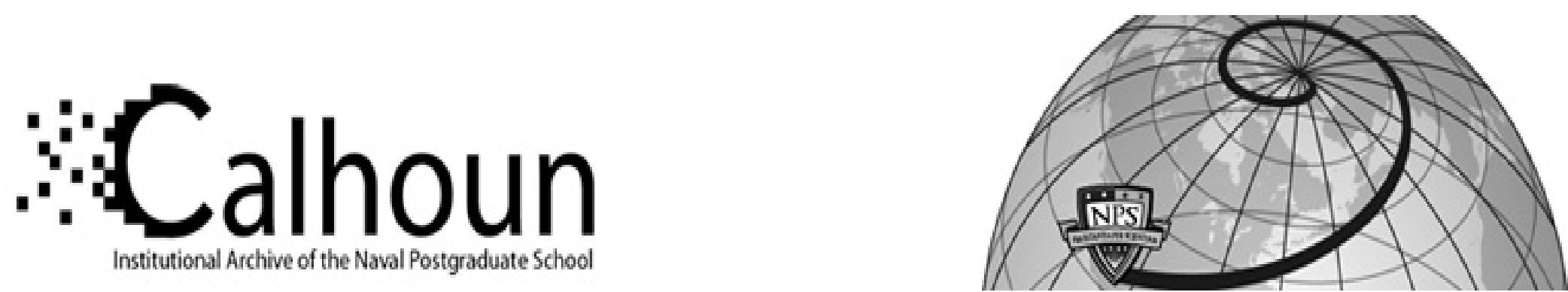

Calhoun: The NPS Institutional Archive DSpace Repository

Texture analysis of the transition from slip to grain boundary sliding in a discontinuously recrystallized superplastic aluminum alloy

Ruano, O.A.; McNelley, T.R.; Pèrez-Prado, M.T.; González-Doncel, G.

Acta mater. Volume 49, (2001), pp. 22592268

https://hdl.handle.net/10945/43193

This publication is a work of the U.S. Government as defined in Title 17, United States Code, Section 101. Copyright protection is not available for this work in the United States.

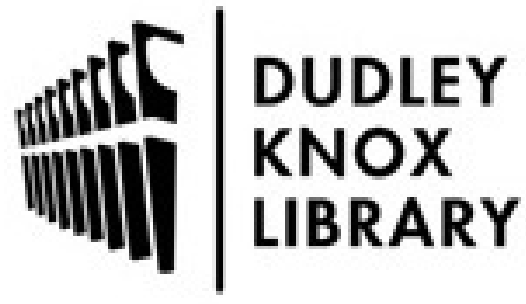

http://www.nps.edu/library
Calhoun is the Naval Postgraduate School's public access digital repository for research materials and institutional publications created by the NPS community. Calhoun is named for Professor of Mathematics Guy K. Calhoun, NPS's first appointed -- and published -- scholarly author.

Dudley Knox Library / Naval Postgraduate School 411 Dyer Road / 1 University Circle Monterey, California USA 93943 


\title{
TEXTURE ANALYSIS OF THE TRANSITION FROM SLIP TO GRAIN BOUNDARY SLIDING IN A DISCONTINUOUSLY RECRYSTALLIZED SUPERPLASTIC ALUMINUM ALLOY
}

\author{
M. T. PÉREZ-PRADO ${ }^{1,2}$, G. GONZÁLEZ-DONCEL ${ }^{1}$, O. A. RUANO ${ }^{1}$ and T. R. \\ MCNELLEY ${ }^{3} \dagger$ \\ ${ }^{1}$ Departamento de Metalurgia Física, Centro Nacional de Investigaciones Metalúrgicas, C.S.I.C., Avda. de \\ Gregorio del Amo 8, 28040 Madrid, Spain, ${ }^{2}$ Department of Mechanical and Aerospace Engineering, \\ University of California-San Diego, 9500 Gilman Drive, La Jolla, CA 92093-0411, USA and \\ ${ }^{3}$ Department of Mechanical Engineering, Naval Postgraduate School, 700 Dyer Road, Monterey, CA \\ 93943-5146, USA
}

( Received 29 December 2000; accepted 15 March 2001)

\begin{abstract}
Texture and microtexture measurements were correlated with mechanical property data for a superplastic 5083 aluminum alloy. Prior processing had included an overaging treatment followed by severe rolling deformation and the as-received material was annealed prior to mechanical testing. Discontinuous recrystallization by particle-stimulated nucleation during the annealing accounts for a predominantly random texture, although a weak $\{100\}<0 v w>$ component was present, as well as a random grain boundary disorientation angle distribution. During elevated temperature deformation under dislocation-creep-controlled conditions, a distinct $\langle 111>$ fiber component and a relatively weak $\{100\}<001>$ cube orientation, which are mutually compatible during uniaxial tensile extension, became apparent in the texture. Also, low-angle boundaries became evident in the disorientation distribution. In contrast, the random texture component and the randomness of the disorientation distribution became more evident when the material was deformed under conditions of grain boundary sliding control of deformation. A transition from dislocation creep to grain boundary sliding observed in the microtexture measurements of this work may be predicted by treating constitutive equations for dislocation creep and grain boundary sliding in an additive manner. Published by Elsevier Science Ltd on behalf of Acta Materialia Inc.
\end{abstract}

Keywords: Aluminum alloys; Recrystallization \& recovery; Grain boundaries; Creep; Superplasticity

\section{INTRODUCTION}

The microstructural prerequisites for superplasticity are now well established. They include fine grain size and grain boundaries capable of sliding while resisting tensile separation $[1,2]$. The need for a fine grain size reflects the independent contributions of grain boundary sliding (GBS) and dislocation creep during elevated temperature deformation [1, 3-5]. According to our current understanding of the physical laws governing creep of polycrystalline materials these mechanisms operate independently and therefore in an additive manner. It follows that the faster of these two mechanisms will control the deformation response at a given temperature and strain rate [6]. This understanding has been derived from phenomenological analysis of extensive mechanical property

\footnotetext{
$\dagger$ To whom all correspondence should be addressed. E-mail address: tmcnelley@nps.navy.mil (T. R. McNelley)
}

data as well as from microstructural observations by optical and electron microscopy [1-6].

GBS and its accommodation are usually envisioned to occur within the boundaries themselves and in adjacent, mantle-like regions of the grains [7, 8]. Accordingly, the deformation rate associated with GBS increases as the grain size becomes finer. In contrast, dislocation creep is presumed to occur independently by dislocation motion within the core regions of the grains and so the deformation rate for dislocation creep is unaffected by changes in grain size. This suggests a grain-size dependent transition in deformation mechanism, and superplasticity at higher strain rates in materials of finer grain size. Such transitions in rate-controlling deformation mechanisms, e.g. from GBS to dislocation creep, should occur over a narrow range corresponding to about an order of magnitude in strain rate [9].

Grain refinement for superplasticity in wrought aluminum alloys can only be achieved by deformation and recrystallization. Empirical approaches 
have led to the development of two distinct thermomechanical processing (TMP) routes, the details of which depend on alloy constitution. For TMP routes involving discontinuous (or primary) recrystallization reactions, overaging treatments are used to develop coarse precipitate particles, $\sim 1 \mu \mathrm{m}$ in size, prior to cold working. These precipitate particles are intended to become sites for particle-stimulated nucleation (PSN) of recrystallization. This involves the formation of high-angle boundaries within the deformation zones around the particles and subsequent high-angle boundary migration into surrounding material [10 14]. Resulting recrystallization textures tend to be random, reflecting random grain orientations due to PSN [14], and there is a predominance of random, high-angle boundaries in the microstructure. For TMPs involving the continuous recrystallization reaction, deformation processing of as-cast material by hot and cold working is accomplished under conditions designed to allow retention of a dispersion of fine $(10-50 \mathrm{~nm})$ second-phase particles. In turn, such particles hinder the migration of high-angle grain boundaries during subsequent thermal treatments or elevated temperature deformation. The term "continuous recrystallization" has been used to describe the recovery-dominated processes that occur in these alloys containing fine, second-phase dispersions [1417]. Well-defined deformation textures and bimodal distributions of grain boundary disorientation angles persist during even prolonged annealing treatments for such materials [18-24]. The disorientation angle is the minimum angle among all crystallographically equivalent rotations that relate two lattice orientations; the term "correlated disorientation" is used here to refer specifically to disorientations of adjacent grains.

Slip processes are influenced by lattice orientation and may also result in characteristic lattice rotations during plastic deformation. On the other hand, GBS is sensitive to disorientation but is thought to result in random grain rotations during elevated temperature flow. Thus, the occurrence of dislocation creep and GBS as well as the interaction between them will be affected by the differences in texture and disorientation for materials representing these different processing routes. Differences in interaction may provide further insight into microstructures developed by processing as well as insight into the dislocation creep and GBS mechanisms.

Previous texture studies on superplastic materials have generally shown an overall reduction in the texture intensity after deformation within the superplastic regime [24-26]. This has usually been attributed to random grain rotation during GBS. It has also been reported that certain texture components become stabilized and that other, new components appear during deformation outside of the superplastic regime; these observations have been attributed to dislocation creep [24, 27-29]. However, considerable controversy exists for many superplastic materials because the sta- bilization of some texture components and the appearance of other, new texture components have also been observed to occur within the superplastic regime. This has usually been interpreted as the result of a joint and simultaneous contribution to the superplastic strain by both dislocation creep processes and GBS over a wide range of rates. However, this is inconsistent with well-accepted creep models which predict that two mechanisms may contribute simultaneously but only over a narrow range of deformation conditions. Furthermore, the relationship between the processing history and the texture of the initial microstructure, or between the texture of the initial and the final, superplastically deformed microstructures, has not been systematically studied. Recent advances in understanding of textures and recrystallization suggest that such relations are critical to interpretation of the material behavior. Furthermore, few studies have considered grain boundary disorientation in relation to processing and mechanisms of recrystallization and deformation for such microstructures [14].

The aim of the present investigation is to evaluate by microtexture methods the transition from dislocation creep to GBS in an alloy that has undergone discontinuous recrystallization. The evolution of the texture from that of the as-received condition to that of various deformed states has been fully characterized and related to the operative deformation mechanisms. Altogether, this work provides a basis for further studies of microstructure-mechanical properties relationships in superplastic materials. Subsequent reports will adopt a similar approach to dislocation creep and GBS in superplastic alloys that undergo a continuous recrystallization reaction.

\section{EXPERIMENTAL PROCEDURE}

The 5083 aluminum alloy of this research was supplied by the manufacturer (SKY) as specially processed for grain refinement and its composition is given in Table 1. While details of the TMP are proprietary, the processing is similar to that initially developed for the 7475 aluminum alloy $[10,11]$. During rolling, deformation zones form around the $\mathrm{Al}_{6} \mathrm{Mn}$ particles and PSN may then take place. The as-received material exhibited a partially recrystallized grain size of about $9 \mu \mathrm{m}$ as determined by mean linear intercept measurement [20, 30].

Tension test samples were prepared with tensile axes either parallel or transverse to the prior rolling direction (RD). Details of the sample geometry have been provided previously [19, 20, 30]. All samples were annealed for $30 \mathrm{~min}$ at $535^{\circ} \mathrm{C}$ prior to subsequent deformation. Constant crosshead speed tension tests were conducted to failure over a wide range of temperatures and nominal strain rates for samples oriented with tensile axes parallel to RD. In selected cases, testing was also conducted with the tensile axis parallel to the transverse direction (TD) of the rolled sheet of the alloy material. Stress-strain curves were 
Table 1. Alloy composition (wt\%)

\begin{tabular}{lllllll}
\hline Alloy & $\mathrm{Mg}$ & $\mathrm{Mn}$ & $\mathrm{Cr}$ & $\mathrm{Fe}$ & $\mathrm{Si}$ & \\
\hline $5083 \mathrm{Al}$ & 4.48 & 0.65 & 0.11 & 0.07 & 0.05 & Bal. \\
\hline
\end{tabular}

flat beyond a nominal strain of about 0.05 , indicating essentially steady state behavior for these testing conditions. Emphasis was placed on testing at $535^{\circ} \mathrm{C}$ because that is the optimum superplastic forming temperature for the alloy.

Macrotexture measurement was carried out on regions close to the mid-thickness of an annealed sample of this material by means of the Schultz reflection method using a diffractometer and closed Eulerian cradle. The (111), (200), (211) and (311) pole figures were obtained. The polar angle ranged from 0 to $90^{\circ}$ in steps of $3^{\circ}$. From the pole figures the even part of the three-dimensional orientation distribution function (ODF) of the Euler angles $\varphi_{1}, \Phi$ and $\varphi_{2}$ was calculated by a series expansion method. Sample preparation consisted of grinding on successively finer silicon carbide papers and final mechanical polishing with $1.0 \mu \mathrm{m}$ diamond paste.

Microtexture measurements were carried out by means of computer-aided EBSP analysis methods. Sample preparation included final electropolishing in a solution of nitric acid and methanol (1:4) at $-22^{\circ} \mathrm{C}$ and $7 \mathrm{~V}$ DC. System hardware was installed on a Topcon SM510 scanning electron microscope (SEM) while system software ran on an SGI Indy computer workstation. The interactive method chosen for data collection has been exhaustively described previously [19-23, 30, 31]. Data sets consisting of 500 individual grain orientations were collected. Microtexture data are presented here in the form of discrete pole figures and correlated (nearest neighbor) disorientation distribution histograms [21, 23]. Finally, microstructures were examined using the SEM operating in the mixed (backscatter and secondary) mode.

\section{RESULTS}

Figure 1 illustrates the microstructure of the 5083 alloy following a $30 \mathrm{~min}$ annealing treatment at $535^{\circ} \mathrm{C}$. An annealing time of $30 \mathrm{~min}$ was chosen because this is approximately the time needed for equilibration at the testing temperature during tension testing. The mean linear intercept value for this microstructure is $12.7 \mu \mathrm{m}$, which indicates slight grain growth relative to the as-received condition. Particles of the $\mathrm{Al}_{6} \mathrm{Mn}$ phase appear dark in Fig. 1; they range up to about $2-3 \mu \mathrm{m}$ in size. The larger particles of this phase tend to be irregular in shape and are aligned with the prior rolling direction. Since $535^{\circ} \mathrm{C}$ is the highest test temperature employed in this study it was anticipated that further grain growth would be minimal upon heating to test temperatures less than $535^{\circ} \mathrm{C}$.

Texture and microtexture data for this condition are

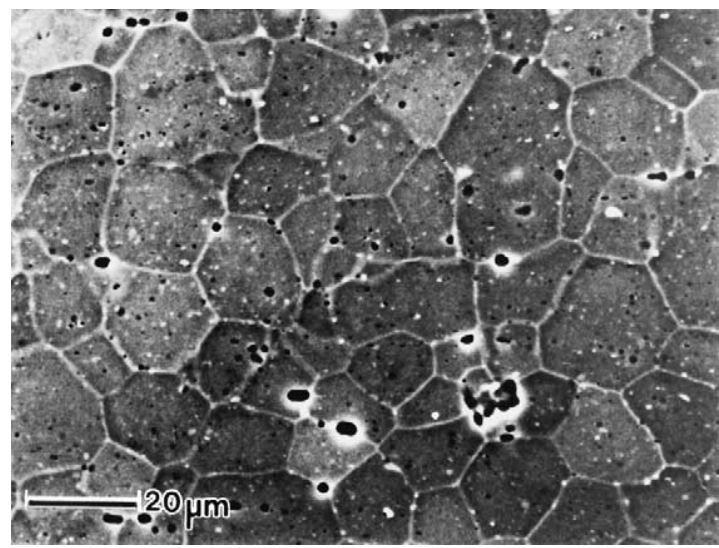

Fig. 1. Microstructure of the 5083 aluminum alloy after annealing at $535^{\circ} \mathrm{C}$ for $30 \mathrm{~min}$. Secondary and backscattered electron image. Orientation contrast, no etchant.

shown in Fig. 2. The texture data are displayed in the form of an ODF [Fig. 2(a)] while the microtexture data are presented in the form of discrete pole figures [Fig. 2(b)] and the corresponding correlated disorientation distribution in the form of a histogram [Fig. 2(c)]. Overall, these data reveal that the distribution of orientations is nearly random but weak texture components are also evident. The ODF data suggest the presence of a weak $\{100\}<0 v w\rangle$ component (reflected in the contours located along the $\varphi_{2}$ axis for all $\varphi_{1}$ sections). This component is also discernable in the $\{200\}$ discrete pole figure as a concentration of poles near the center as well as in an approximately uniform distribution of poles around the periphery. A weak Goss component $\left(\{110\}<100>\right.$, or $\varphi_{1}=0^{\circ}$, $\Phi=45^{\circ}$, and $\varphi_{2}=0^{\circ}$ ) is also evident in the ODF [Fig. $2(a)]$ and may also be reflected in the $\{220\}$ discrete pole figure as in the concentration of poles in the center [Fig. 2(b)]. This was present in the as-received material [20, 30] and has become slightly stronger in this annealed condition. A very weak $\mathrm{Cu}$ texture component $\left(\{112\}<111>\right.$, or $\varphi_{1}=90^{\circ}, \Phi=30^{\circ}$ and $\varphi_{2}=45^{\circ}$ ) was present in the as-received material but is no longer discernable following this annealing treatment. The discrete pole figures demonstrate most clearly the predominance of the random component in the texture. The correlated disorientation distribution exhibits a peak at $40-45^{\circ}$, and is close to that predicted by Mackenzie for the disorientations of randomly oriented cubes [32]; such a distribution is consistent with the predominance of the random component in the texture. Altogether the microstructure and texture data reflect grain refinement by PSN of recrystallization during the prior processing and final annealing of this material. 
(a)

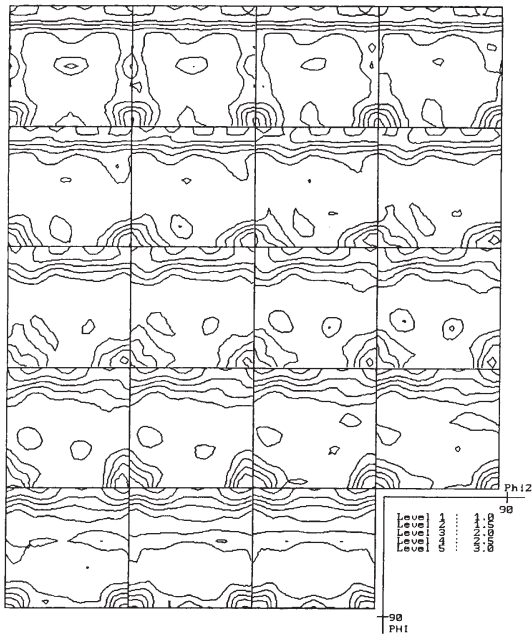

(b)

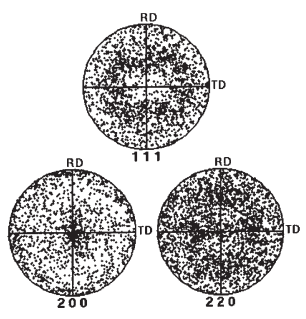

(c)

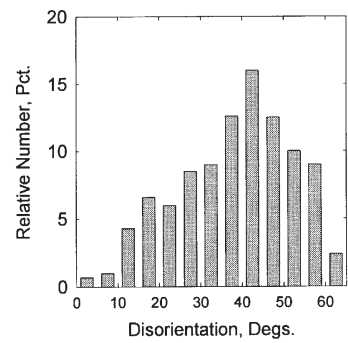

Fig. 2. Texture data for the annealed 5083 aluminum alloy in the form of (a) the ODF determined by X-ray methods; (b) discrete pole figures determined by EBSD methods; and (c) a histogram representing the distribution of disorientation angles for adjacent grains.

The results of the mechanical testing are summarized in Figs 3 and 4. Data are included for tests conducted with the tensile axis parallel to the final rolling direction (filled symbols) as well as for tests in the transverse orientation (open symbols). In Fig. 3 the data are plotted on double logarithmic axes as the flow stress at a true strain of $0.1, \sigma_{\varepsilon=0.1}$, vs the nominal strain rate, $\dot{\varepsilon}$. The stress exponent, $n$ (d $\log \dot{\varepsilon} / \mathrm{d} \log \sigma$ ), has a value of about 1.5 at the lowest strain rates for testing conducted at $T=535^{\circ} \mathrm{C}$; the $n$-value increases for testing conducted at higher strain rates and a transition is apparent at a strain rate $\approx 2 \times 10^{-3} \mathrm{~s}^{-1}$. Above this strain rate the stress exponent increases to a value of $\approx 5$. For the two lower test temperatures employed here a value of $n \approx 5$ was also obtained, although fewer tests were conducted at these temperatures. An apparent activation energy value for deformation, $140 \mathrm{~kJ} / \mathrm{mol}$, may be estimated from these data. Binary $\mathrm{Al}-\mathrm{Mg}$ alloys containing from 2.2 up to $10 \mathrm{wt} \% \mathrm{Mg}$ have been shown to exhibit stress exponents of $n \approx 3$ and apparent activation energies of about $136 \mathrm{~kJ} / \mathrm{mol}$ in this temperature and strain rate regime, values which are indicative of solute-drag control of creep [33]. However, recent work $[34,35]$ has demonstrated that ter-

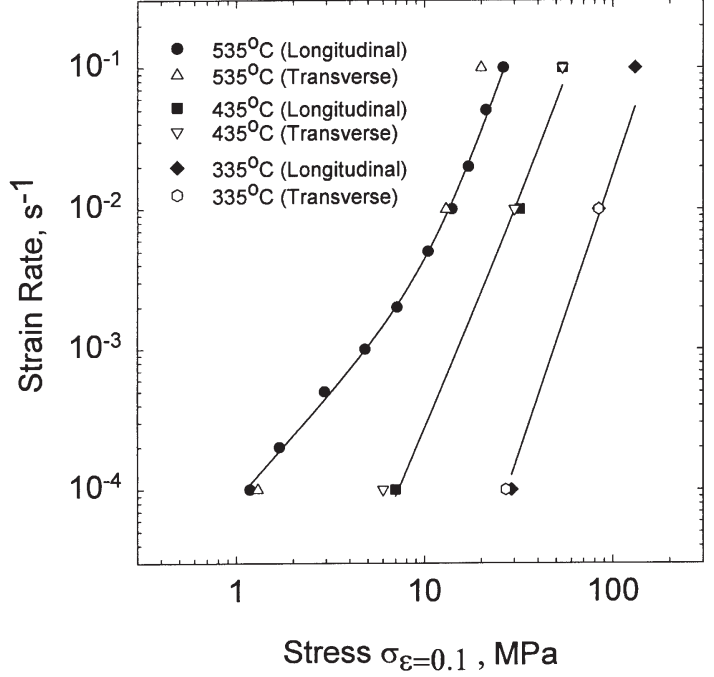

Fig. 3. The strain rate as a function of stress at various temperatures for tests conducted with the tensile axis parallel to the final rolling direction (filled symbols) as well as for tests in the transverse orientation (open symbols).

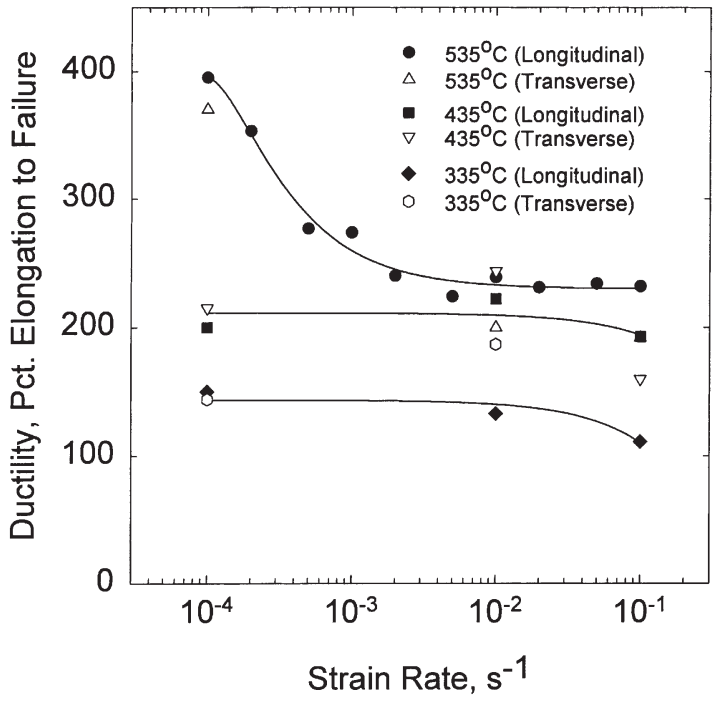

Fig. 4. The elongation to failure as a function of strain rate at various temperatures for tests conducted with the tensile axis parallel to the final rolling direction (filled symbols) as well as

for tests in the transverse orientation (open symbols).

nary additions of $0.25 \mathrm{wt} \% \mathrm{Mn}$, or more, in $\mathrm{Al}-\mathrm{Mg}-$ Mn alloys result in an increase in the stress exponent to a value of between 4 and 5 while activation energy values remain at about $140 \mathrm{~kJ} / \mathrm{mol}$. The increase in the stress exponent, $n$, to a value similar to that for pure metal behavior has been attributed to an effective reduction of $\mathrm{Mg}$ content due to interaction between the Mg and Mn solutes [34].

Elongations to failure data obtained here are shown in Fig. 4. The maximum ductility of about $400 \%$ elongation was obtained for testing conducted at the lowest strain rate and $T=535^{\circ} \mathrm{C}$. This corresponds to the smallest $n$, which, in turn, gives the largest strain 
rate sensitivity coefficient $m(=1 / n)$. The ductility decreased for higher strain rates and lower ductilities were also obtained at the lower test temperatures. Finally, Figs 3 and 4 suggest isotropic behavior for this material as can be deduced by comparing the data obtained from testing in the TD to corresponding data from the RD tests.

Microtexture measurements were employed to characterize the deformation mechanisms associated with the two regimes ( $n \approx 5$ and $n<2)$ apparent in the mechanical property data of Fig. 3. A stress exponent of 5 is consistent with deformation under dislocation creep conditions. Samples deformed to failure under dislocation creep conditions (at $335^{\circ} \mathrm{C}$ and $\dot{\varepsilon}=10^{-2} \mathrm{~s}^{-1}$ for tensile axes parallel to both the RD and TD of the rolled sheet; and at $535^{\circ} \mathrm{C}$ and $\dot{\varepsilon}=10^{-1} \mathrm{~s}^{-1}$ for the tensile axis parallel to RD) were selected as representative of this regime. Discrete pole figures and correlated disorientation distribution histograms are shown in Fig. 5 for the tests conducted at $335^{\circ} \mathrm{C}$. Distinct $\langle 111>$ fiber textures, wherein the $<111>$ fiber axis is aligned with the tensile axis, have become apparent for both sample orientations. These $<111>$ fiber textures are most obvious in the $\{111\}$ and $\{220\}$ pole figures. In Fig. 5(a) the bands indicate rotational symmetry about $\mathrm{RD}$, which, in turn, is the sample's tensile axis. The $\{111\}$ poles are aligned with the RD and in bands at about $70.5^{\circ}$ to RD, while in the $\{220\}$ pole figure the corresponding bands are located at about 35.3 and $90^{\circ}$ to the RD. These same features are apparent in Fig. 5(b) but the bands indicate rotational symmetry about $\mathrm{TD}$, which is the ten-
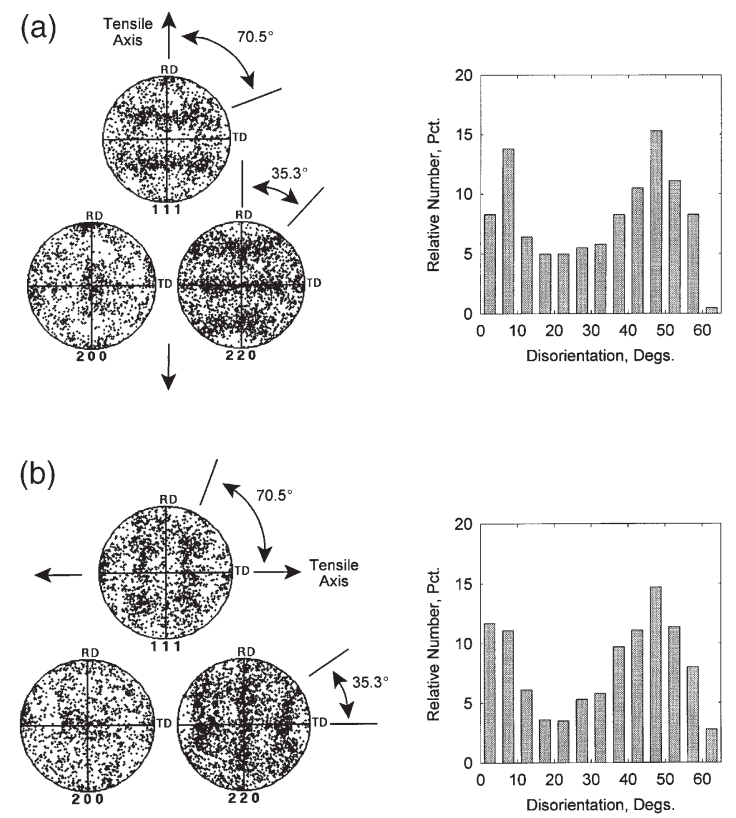

Fig. 5. Discrete pole figures and histograms of the correlated misorientation distributions for 5083 aluminum deformed in the dislocation creep regime at $335^{\circ} \mathrm{C}$ and $10^{-2} \mathrm{~s}^{-1}$. Data for tension testing parallel to RD are shown in (a), and for tension testing parallel to TD are shown in (b). sile axis for this sample. The appearance of a $<111>$ fiber texture reflects lattice rotation due to slip and six slip systems of the fcc lattice have equal resolved shear stress in this orientation. The $\{200\}$ pole figures for both sample orientations reveal concentrations of poles along the rolling, transverse and normal directions, suggesting the development of a $\{100\}<001>$ cube component in the texture as well. This texture component has eight equally stressed fcc slip systems. Finally, grains with $\langle 110\rangle$ near the tensile axis in either Fig. 5(a) or (b) have rotated away from this orientation. This may be seen by comparing the distributions of poles in the $\{220\}$ discrete pole figures of Fig. 2(b) and Figs 5(a) and (b).

The correlated disorientation histograms for both sample tensile axis orientations exhibit two peaks. Comparison with the disorientation data for the annealed condition suggests that the low-angle peak (at $5-10^{\circ}$ ) for both sample orientations is the result of deformation, and may reflect substructure formation by recovery of slip dislocations. While a pure fiber texture would result in an equal population of boundaries in all disorientation ranges in such histograms the pole figures also indicate a large population of random orientations. Following Mackenzie, this is consistent with the peak near $45^{\circ}$ in these histograms. Thus, the disorientation data are consistent with the superposition of a distribution due to substructure formation by recovery following slip upon a distribution due to the initial, random grain orientations in the microstructure and a weak fiber. Finally, Fig. 6 illustrates grain elongation during tensile straining for dislocation creep control of deformation at this temperature $\left(535^{\circ} \mathrm{C} / 10^{-2} \mathrm{~s}^{-1}\right)$. Extensive additional precipitation of the $\mathrm{Al}_{8} \mathrm{Mg}_{5}$ phase on grain boundaries and within the grains is also evident.

Figure 7 illustrates the microtexture data corresponding to this 5083 alloy following deformation at $535^{\circ} \mathrm{C}$ and a strain rate of $10^{-1} \mathrm{~s}^{-1}$ along the RD.

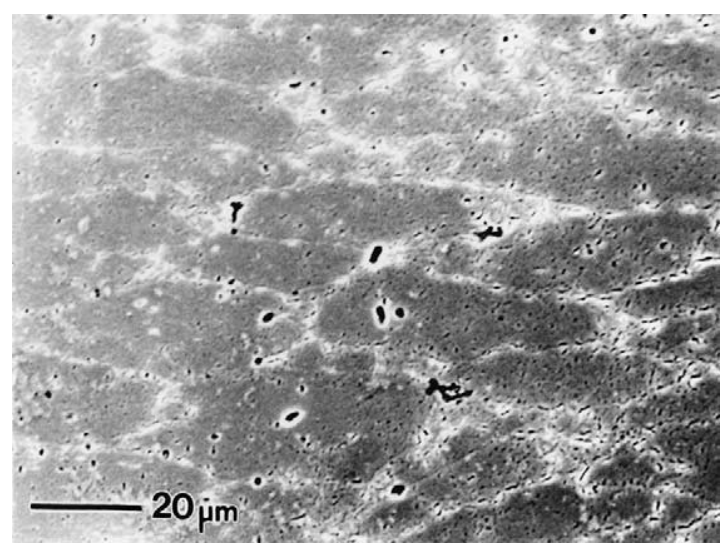

Fig. 6. The microstructure of the 5083 aluminum alloy following tensile deformation at $335^{\circ} \mathrm{C}$ and $10^{-2} \mathrm{~s}^{-1}$, showing grain elongation parallel to the tensile axis. Precipitation of the $\mathrm{Al}_{8} \mathrm{Mg}_{5}$ phase, especially on the grain boundaries, is evident. Secondary and backscatter electron image, orientation contrast, no etchant. 

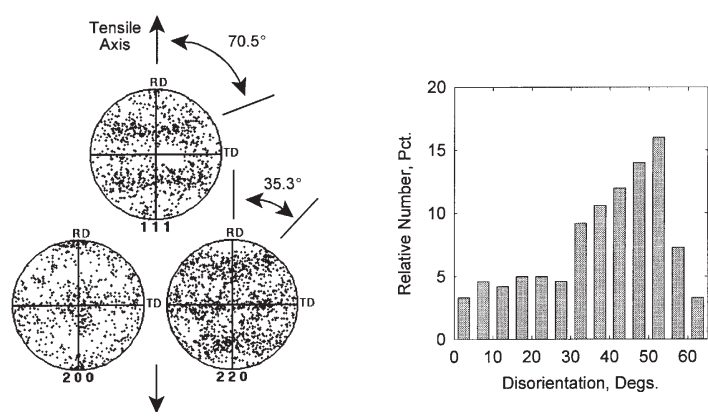

Fig. 7. Microtexture data in the form of discrete pole figures and a histogram of the distribution of the correlated misorientation angles for the 5083 aluminum alloy deformed in the dislocation creep regime at $535^{\circ} \mathrm{C}$ and $10^{-1} \mathrm{~s}^{-1}$.

The stress exponent, $n$, is again about 5 for these conditions (Fig. 3). A $\langle 111>$ fiber texture and the $\{100\}<001>$ cube component are both apparent, but comparison with Fig. 5 reveals that these components are both less distinct in the pole figures than they were for deformation at the lower temperature. Also, the relative population of low-angle boundaries is lower for this condition. This is consistent with the development of a coarser substructure and lower subboundary disorientations for deformation at this higher temperature (and lower stress).

Microtexture data are shown in Fig. 8 that correspond to tests performed along the RD [Fig. 8(a)] and along the TD [Fig. 8(b)] under optimum superplastic conditions $\left(535^{\circ} \mathrm{C}\right.$ and $\left.10^{-4} \mathrm{~s}^{-1}\right)$. The stress exponent, $n$, is about 1.5 for these conditions and the tensile
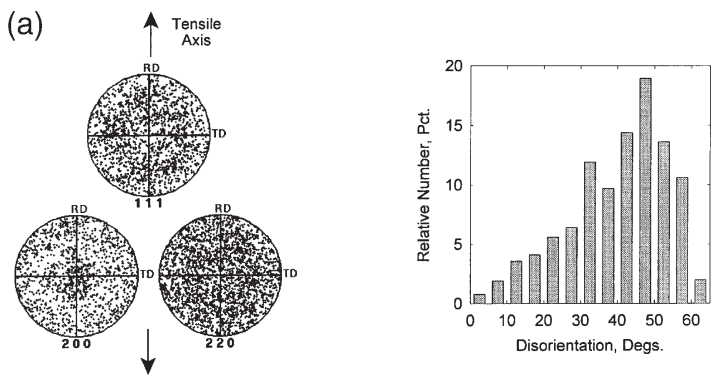

(b)
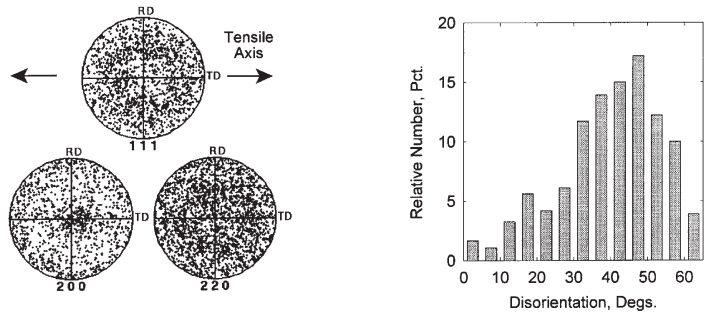

Fig. 8. Discrete pole figures and histograms of the correlated misorientation distributions for 5083 aluminum deformed in the GBS regime at $535^{\circ} \mathrm{C}$ and $10^{-4} \mathrm{~s}^{-1}$. Data for tension testing parallel to RD are shown in (a), and for tension testing parallel to TD are shown in (b). ductility values are $375-400 \%$ elongation to failure. The $\langle 111>$ fiber does not form for these deformation conditions and the $\{111\}$ and $\{220\}$ pole figures suggest randomization of texture, which is consistent with GBS. However, a weak $\{100\}<0 v w\rangle$ component can still be seen in the $\{200\}$ pole figure. This component was evident in the annealed condition and may be slightly less well defined after deformation here; however it is apparently stable against random grain rotations during deformation by GBS. Again, the deformation behavior is isotropic for these data. The micrograph in Fig. 9 illustrates the absence of grain elongation during deformation under conditions of GBS control of deformation. Comparison with Fig. 1 reveals that grain growth has occurred but grains remain equiaxed. This is indicative of the absence of slip processes during straining in these conditions.

\section{DISCUSSION}

Processing history governs microstructure and thereby controls the mechanical behavior of engineering alloys. The 5083 alloy of this research is a typical example of aluminum alloys processed utilizing PSN of recrystallization to achieve a uniform, refined grain structure capable of superplastic response.

\subsection{The initial, annealed microstructure}

The conditions for PSN of recrystallization are reasonably well known although many details remain to be determined. Severe low-temperature deformation of a particle-containing alloy results in the development of deformation zones around the particles. PSN during annealing tends to occur most readily for coarse dispersed particles and, from a practical viewpoint, the minimum particle size for PSN is apparently about $1 \mu \mathrm{m}$. Grain orientations associated with PSN tend to be random because of the large spread of lattice orientation around the particles

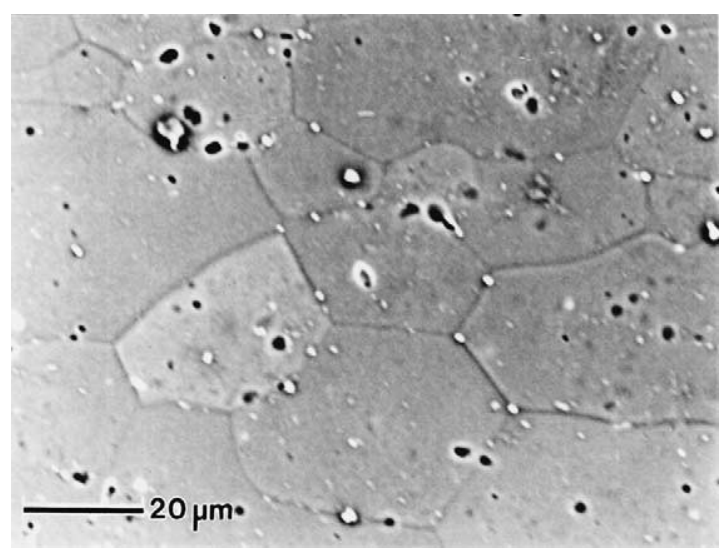

Fig. 9. The microstructure of the 5083 aluminum alloy following tensile deformation in the $\mathrm{GBS}$ regime at $535^{\circ} \mathrm{C}$ and $10^{-4}$ $\mathrm{s}^{-1}$. Grain growth is evident, as revealed by comparison with the microstructure of the annealed condition in Fig. 1. Secondary and backscatter electron image, orientation contrast, no etchant. 
following the prior deformation of the material. In general, recrystallization after deformation produces preferred orientation in materials; PSN is one of the few recrystallization mechanisms available to produce random textures in wrought aluminum alloys. This is an important mechanism since a fine grain structure with random grain orientations and highangle grain boundaries are prerequisites for superplastic response. As can be seen in Fig. 2, some faint texture components are also apparent in the asreceived material. Such non-random recrystallization texture components are often seen in particle-containing alloys and their presence may reflect one or more of several factors [14]. These include the formation of other types of recrystallization nuclei in local regions, preferential PSN for particles located on prior grain boundaries, and selective growth of some orientations among those produced by PSN.

\subsection{Mechanical behavior at elevated temperature}

The microstructure in Fig. 1 is implicit in constitutive models of the elevated temperature mechanical behavior of polycrystalline materials. Because the orientations of grains are determined by random processes there are no orientation relationships between adjacent grains and there is a predominance of highangle grain boundaries in the microstructure. For homogeneous, compatible deformation among randomly oriented grains in a polycrystalline metal Taylor's analysis specifies that a minimum of five independent slip systems must be available for deformation by intragranular dislocation motion [36]. On the other hand, deformation by GBS requires disordered, high-angle grain boundaries (although the minimum disorientation necessary for this mechanism remains to be established). The disorientation for randomly oriented grains will meet this latter requirement.

A stress exponent of 5 coupled with an activation energy near that for self-diffusion in aluminum suggests lattice-diffusion controlled dislocation creep for the higher strain rate data obtained at $535^{\circ} \mathrm{C}$ and for all the data at the lower two test temperatures. A general constitutive law for lattice-diffusion controlled dislocation creep in polycrystalline metals of high stacking fault energy metals is given by $[1,2,4,5]$

$$
\dot{\varepsilon}_{\text {slip }}=10^{11}\left(\frac{D_{\mathrm{L}}}{b^{2}}\right)\left(\frac{\sigma}{E}\right)^{5}
$$

where $\dot{\varepsilon}_{\text {slip }}$ is the dislocation creep strain rate $\left(\mathrm{s}^{-1}\right)$, $D_{\mathrm{L}}$ is the lattice diffusivity $\left(\mathrm{m}^{2} \mathrm{~s}^{-1}\right), b$ is the Burger's vector (m), $\sigma$ is the flow stress, and $E$ is the dynamic, unrelaxed Young's modulus for the temperature in question ( $\sigma$ and $E$ in $\mathrm{MPa}$ ). Similarly, a constitutive equation for the lower stress exponent regime observed during low strain rate testing at $535^{\circ} \mathrm{C}$ is $[1$, $2,4,5]$

$$
\dot{\varepsilon}_{\mathrm{GBS}}=2 \times 10^{9}\left(\frac{D_{\mathrm{L}}}{\bar{L}^{2}}\right)\left(\frac{\sigma}{E}\right)^{2}
$$

where $\dot{\varepsilon}_{\mathrm{GBS}}$ is the strain rate due to GBS $\left(\mathrm{s}^{-1}\right)$, and $\bar{L}$ is the mean linear intercept grain size (m). Together, these equations suggest that the data of Fig. 3 may be replotted in normalized form as $\varepsilon / D_{\mathrm{L}}$ vs $\sigma / E$. Lattice diffusivity and dynamic Young's modulus data for pure aluminum were used in the absence of specific data for this aluminum-magnesium alloy and the results are plotted in Fig. 10. The data fall on a single curve (indicated by the solid line) with a transition from $n \approx 1.5$ to $n \approx 5$ at $\varepsilon / D_{\mathrm{L}} \approx 5 \times 10^{10} \mathrm{~m}^{-2}$.

With the assumption that dislocation creep and GBS contribute in an independent, additive manner to the total deformation rate, $\dot{\varepsilon}_{T}$, the mechanical behavior of this alloy may be modeled in terms of equations (1) and (2) as

$$
\dot{\varepsilon}_{\mathrm{T}}=\dot{\varepsilon}_{\mathrm{slip}}+\dot{\varepsilon}_{\mathrm{GBS}}
$$

where $\dot{\varepsilon}_{\text {slip }}$ and $\dot{\varepsilon}_{\mathrm{GBS}}$ are given by equations (1) and (2), respectively. Since $D_{\mathrm{L}}$ appears in both equations (1) and (2), equation (3) may be written in the form

$$
\frac{\dot{\varepsilon}_{\mathrm{T}}}{D_{\mathrm{L}}}=\frac{10^{11}}{b^{2}}\left(\frac{\sigma}{E}\right)^{5}+\frac{2 \times 10^{9}}{\bar{L}^{2}}\left(\frac{\sigma}{E}\right)^{2}
$$

Equation (4) is plotted as the dashed line in Fig. 10 while equations (1) and (2) are indicated separately

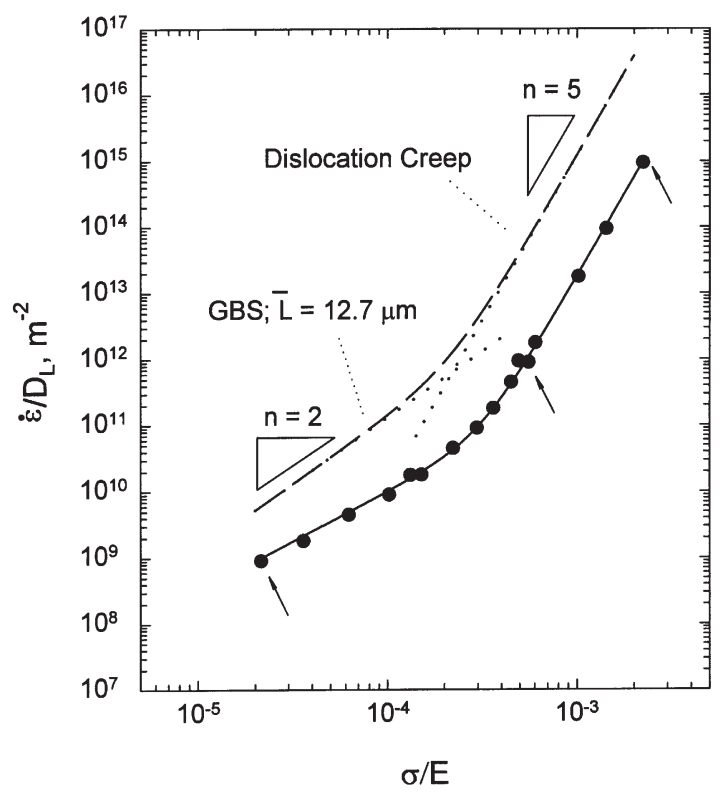

Fig. 10. Lattice-diffusion compensated strain rate as a function of modulus compensated stress for the 5083 aluminum alloy. The predictions of the dislocation creep and GBS models are shown as the dashed line. The arrows indicate the conditions investigated by EBSP analysis methods. 
by dotted lines; $\bar{L}$ was assumed equal to $12.7 \mu \mathrm{m}$. The model is in good agreement with the experimental data. Equation (4) correctly predicts the stress level for the observed transition from GBS to dislocation creep control of deformation. The transition is predicted to take place over a little more than an order of magnitude in strain rate, which is consistent with the shape of the solid curve fitting the experimental data. However, equation (4) overestimates the deformation rate by about one and one-half orders of magnitude.

\subsection{Variation of microtexture during dislocation creep}

The microtexture data had been obtained on samples each corresponding to one of the three points indicated by the arrows below the data points on Fig. 10. Data for the samples deformed in the dislocation creep region were obtained following deformation at the two highest values of diffusion-compensated strain rate: $9 \times 10^{13} \mathrm{~m}^{-2}$ and about $10^{12} \mathrm{~m}^{-2}$. The microtexture data are presented in Figs 5 and 7 , respectively. In both cases, $\langle 111\rangle$ fiber and $\{100\}<001>$ cube texture components became apparent. As illustrated in the upper schematic of Fig. 11, grains in either of these two orientations meet Taylor's requirement for compatible and homogeneous deformation during axially symmetric flow. Six slip systems each have equivalent Schmid factors for a grain oriented with $<111>$ parallel to the fiber axis, while eight slip systems have the same Schmid factor for a $\{100\}<001>$ cube grain (see Table 2). Fiber textures consisting of prominent $\langle 111\rangle$ and weak $<001>$ texture components are usually observed in drawn wires and extruded bars of high stacking fault energy fcc metals [37, 38], although a weak $\{100\}<001>$ cube component is observed in the present work rather than a $<001>$ fiber component.

It is deemed likely that the grains with the $\{100\}<001>$ cube orientation in material deformed under dislocation creep conditions evolved by slipinduced lattice rotation from among the population of $\{100\}\langle 0 v w\rangle$ grains in the material. This may occur more readily than formation of a $<001>$ fiber. Then, the $<111>$ fiber component mainly reflects reorientation of grains initially within the random population.

The $<111>$ fiber and $\{100\}<001>$ cube texture components represent mutually stable end orientations during uniaxial tensile deformation under dislocation creep conditions. This may be shown using an approach described by Hosford [39]. The specific orientations used for the following calculations are given in Table 2. It is assumed that each one of the six active slip systems in a grain belonging to the $<111>$ fiber texture component experiences the same incremental plastic shear distortion $\mathrm{d} \xi$. The corresponding incremental distortion for the grain may then be calculated by summing the individual contribution from each of the six active slip systems. When (a)

Dislocation creep control of
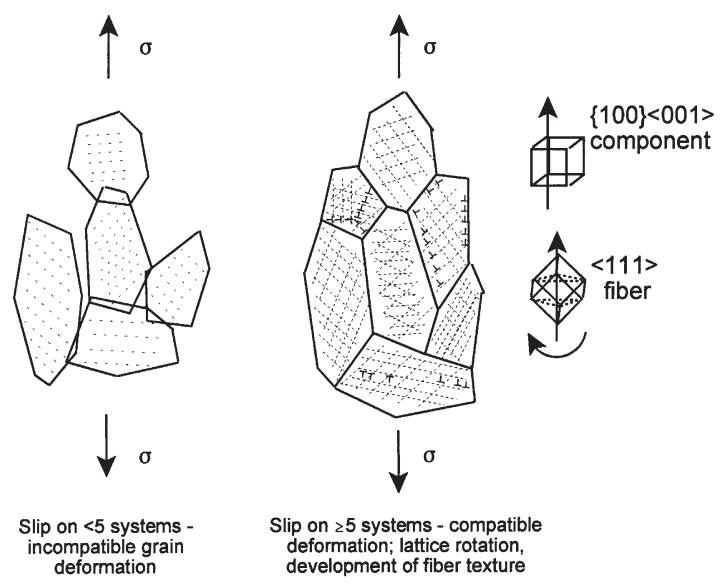

(b)

Superplastic deformation with GBS and slip or diffusional accomodation of deformation

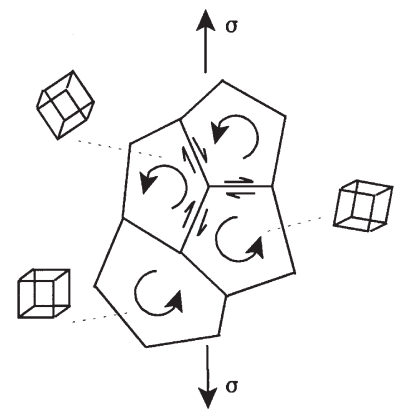

Grain boundary sliding + random grain rotations

Fig. 11. Schematic representations of deformation under dislocation creep conditions (a) wherein slip in randomly oriented grains results in formation of a $<111>$ fiber texture; in $\{100\}\langle 0 v w\rangle$ grains, lattice rotation results in the appearance of a $\{100\}<001>$ component. Under GBS control of deformation (b) random grain rotations result in a predominantly random texture after deformation.

expressed in the sample axis system (RD, TD and ND) this corresponds to an incremental strain for such a grain; in tensor form it is

$$
\mathrm{d} \varepsilon^{\langle 111\rangle^{\prime}}=\mathrm{d} \xi\left(\begin{array}{ccc}
1.631 & 0 & 0 \\
0 & -0.816 & 0 \\
0 & 0 & -0.816
\end{array}\right)
$$

i.e., the grain exhibits axisymmetric elongation for RD as the tensile axis. In the summation of the contributions from all slip systems to the sample distortion, the off-diagonal terms related to lattice rotation add to zero, leaving only shape change. The active slip 
Table 2. Schmid factors for (a) [111] parallel to the tensile axis and (b) for the (100)[001] orientation

\begin{tabular}{|c|c|c|c|}
\hline Slip plane & Slip direction & (a) & (b) \\
\hline \multirow[t]{3}{*}{ (111) } & {$[0 \overline{1} 1]$} & 0 & -0.408 \\
\hline & [1]01] & 0 & 0.408 \\
\hline & {$[1 \overline{1} 0]$} & 0 & 0 \\
\hline \multirow[t]{3}{*}{ (1111) } & {$[0 \overline{1} \overline{1}]$} & -0.272 & 0.408 \\
\hline & [101] & 0.272 & -0.408 \\
\hline & {$[\overline{1} 10]$} & 0 & 0 \\
\hline \multirow[t]{3}{*}{$(11 \overline{1})$} & {$[01 \overline{1}]$} & 0 & -0.408 \\
\hline & [101] & 0.272 & 0.408 \\
\hline & {$[\overline{1} \overline{1} 0]$} & -0.272 & 0 \\
\hline \multirow[t]{3}{*}{$(1 \overline{1} 1)$} & {$[0 \overline{1} \overline{1}]$} & -0.272 & -0.408 \\
\hline & {$[\overline{1} 01]$} & 0 & 0.408 \\
\hline & {$[110]$} & 0.272 & 0 \\
\hline
\end{tabular}

systems occur in conjugate pairs and so the grain may continue to elongate without further lattice rotation. Similarly, for an incremental shear distortion $\mathrm{d} \zeta$ on each of the eight active slip systems in an $\{100\}<001>$ cube grain the incremental strain is

$$
\mathrm{d} \varepsilon^{\{100\}\langle 001\rangle^{\prime}}=\mathrm{d} \zeta\left(\begin{array}{ccc}
3.263 & 0 & 0 \\
0 & -1.632 & 0 \\
0 & 0 & -1.632
\end{array}\right)
$$

and, again, such a grain may elongate in uniaxial tension without lattice rotation. It also follows that grains in these different orientations are able to undergo shape changes consistent with uniaxial extension. The incremental shears will be different for grains of these two orientations but the grains may deform without mutual interference and so these two orientations are mutually stable during deformation under dislocation creep conditions.

Finally, grains in the random population oriented with a $<110>$ parallel to the tensile axis have four slip systems with equivalent, non-zero Schmid factors. Such grains would not experience an incremental distortion that is compatible with uniaxial tension. For this reason, the $\langle 110\rangle$ fiber orientation is not stable and this is consistent with the decrease in the population of grains with this orientation as noted in comparison of the discrete $\{220\}$ pole figures of Figs 5(a) and (b) with those of Fig. 2(b).

\subsection{Variation of microtexture in relation to $G B S$}

The variation of texture with deformation conditions shown in this work corresponds well with that predicted by the operation of two independent deformation mechanisms: dislocation creep at high diffusion-compensated strain rates giving way to GBS as the diffusion-compensated strain rate decreases. The transition from dislocation creep to GBS appears to begin as the modulus compensated stress, $\sigma / E$, decreases below about $6 \times 10^{-4}$. At this stress, GBS apparently begins to contribute appreciably to the total deformation rate and this is seen in the microtex- ture data of Fig. 7 for the sample deformed for conditions within the transition region. These data shows a less distinct $\langle 111\rangle$ fiber texture than observed in the sample deformed entirely in the slip region (Fig. $5)$. Conversely, the data for the sample deformed entirely within the GBS at $\sigma / E \approx 2 \times 10^{-5}$ show primarily an enhancement of the random component in the texture.

The presence of a weakened $\{100\}<0 \mathrm{vw}>$ orientation even after an elongation of $400 \%$ under GBS conditions is consistent with the texture weakening normally associated with GBS. This is illustrated in the lower schematic of Fig. 11. Lattice rotation associated with GBS is often reported to be relatively slow and this may be reflected here as an apparent stability of this component.

These microtexture data demonstrate that the transition from dislocation creep to GBS takes place as anticipated in phenomenological models that consider these mechanisms to operate in an independent, additive manner. The initially weak texture only weakens further during deformation under GBS control of deformation in the superplastic regime, while a deformation texture develops during deformation in the dislocation creep regime. The foregoing is consistent with the premise that grain orientations in the microstructure are random in nature. Thus, the behavior described is characteristic of superplastic aluminum alloys that have experienced discontinuous recrystallization reactions via PSN during processing. For aluminum alloys that exhibit continuous recrystallization reactions preferred orientation and orientation relationships within the microstructure may alter this pattern of behavior; this will be the subject of future reports.

\section{CONCLUSIONS}

The following conclusions may be drawn from this work.

1. Grain refinement of 5083 aluminum for superplasticity using PSN of discontinuous recrystallization results in random grain orientations, with mainly high-angle boundaries in the microstructure. 
2. Dislocation creep and GBS contribute independently and additively to the deformation rate during elevated temperature tensile straining for such a microstructure.

3. When dislocation creep predominates, a $<111>$ fiber and a $\{100\}<001>$ cube component develop in the texture. These components reflect Taylor's requirement of five or more independent mechanisms for homogeneous, compatible deformation of a random polycrystal under uniaxial tensile extension, and they are also mutually compatible end orientations for uniaxial tensile deformation.

4. For dislocation creep control of deformation the activation energy was equal to that for lattice selfdiffusion while the stress exponent, $n$, was 5. A transition to GBS control occurred over about one and one-half orders of magnitude in strain rate; GBS control of deformation was reflected in a value for the stress exponent, $n$, of about 1.5 , while the activation energy was again equal to that for lattice self-diffusion. The independent contributions of dislocation creep and GBS may be modeled by addition of constitutive laws for these mechanisms and the resulting relationship accurately reflects the mechanical behavior of this material.

5. Conversely, when GBS is the predominant deformation mode the random component in the texture is enhanced although retention of a weakened $\{100\}\langle 0 v w\rangle$ component reflects slow grain rotation in association with this mechanism.

Acknowledgements - The authors gratefully acknowledge the financial support of the CICYT under grant MAT97/0700.

\section{REFERENCES}

1. Sherby, O. D. and Ruano, O. A., in Superplastic Forming of Structural Alloys, ed. N. E. Paton and C. H. Hamilton. TMS-AIME, New York, 1982, p. 241.

2. Ruano, O. A. and Sherby, O. D., Rev. Metal. Madrid, 1983, 19, 261.

3. Langdon, T. G., Metall. Trans. A, 1982, 13A, 689.

4. Sherby, O. D. and Wadsworth, J., in Deformation Processing and Microstructure, ed. G. Krauss. ASM, Materials Park, OH, 1984, p. 355.

5. Ruano, O. A. and Sherby, O. D., Rev. Phys. Appl., 1988, 23, 625 .

6. Poirier, J. P., in Creep of Crystals. Cambridge University Press, 1985 , p. 79.

7. Gifkins, R. C., Metall. Trans. A, 1976, 7A, 1225.

8. Ball, A. and Hutchison, M. M., Met. Sci. J., 1969, 3, 1.
9. Ruano, O. A., Miller, A. K. and Sherby, O. D., Mater. Sci. Eng., 1981, 51, 9.

10. Waldman, J., Sulinski, H. and Markus, H., Metall. Trans. A, 1974, 5, 573

11. Wert, J. A., Paton, N. E., Hamilton, C. H. and Mahoney, M. W., Metall. Trans. A, 1981, 12A, 1267.

12. Paton, N.E. and Hamilton, C. H., US Patent No. 4,092,181, 1978.

13. Humphreys, F. J., Acta metall., 1977, 25, 1323.

14. Doherty, R. D., Hughes, D. A., Humphreys, F. J., Jonas, J. J., Juul Jensen, D., Kassner, M. E., King, W. E., McNelley, T. R., McQueen, H. J. and Rollett, A. D., Mater. Sci. Eng. A, 1997, A238, 219.

15. Grimes R., NATO-AGARD Lecture Series No. 168, 8.18.16, 1988.

16. Watts, B. M., Stowell, M. J., Baike, B. L. and Owen, D. G. E., Metal. Sci. J., 1976, 10, 189.

17. Hornbogen, E., Metall. Trans. A., 1979, 10A, 947.

18. Chokshi, A. H., Mukherjee, A. K. and Langdon, T. G., Mater. Sci. Eng., 1993, R10, 237.

19. McNelley, T. R. and McMahon, M. E., Metall. Mater. Trans. A, 1996, 27A, 2252.

20. McNelley, T. R., McMahon, M. E. and Hales, S. J., Scripta mater., 1997, 36, 369.

21. McNelley, T. R. and McMahon, M. E., Metall. Mater. Trans. A, 1997, 28A, 1879.

22. Pérez-Prado, M. T., McNelley, T. R., Ruano, O. A. and González-Doncel, G., Metall. Mater. Trans. A, 1998, 29A, 485.

23. McNelley, T. R., McMahon, M. E. and Pérez-Prado, M. T., Phil. Trans. A, 1999, 357, 1683.

24. Edington, J. W., Melton, K. N. and Cutler, C. P., Prog. Mater. Sci., 1976, 21, 63.

25. Padmanabhan, K. A. and Lücke, K., Z. Metallkde., 1986, 7, 765 .

26. Hirsch, J. R., Mater. Sci. Technol., 1990, 6, 1048.

27. Kaibyshev, O. A., Rodionov, B. V. and Valiev, R. Z., Acta metall., 1978, 26, 1877.

28. Kaibyshev, O. A., Kazachkov, I. V. and Galeev, R. M., J. Mater. Sci., 1981, 16, 2501.

29. Matsuki, K., Morita, H., Yamada, M. and Murakami, Y., Met. Sci., 1977, 6, 156.

30. McMahon M. E., Ph.D. Thesis, Naval Postgraduate School, Monterey, CA, 1996.

31. McNelley, T. R. and McMahon, M. E., J. Met., 1996, 48(2), 58

32. Mackenzie, J. K., Biometrica, 1958, 45, 229.

33. McNelley, T. R., Michel, D. J. and Salama, A., Scripta metall., 1989, 23, 1657.

34. Taleff, E. M., Henshall, G. A., Nieh, T. G., Lesuer, D. R. and Wadsworth, J., Metall. Mater. Trans. A, 1998, 29A, 1081.

35. Hsiao, I. C., Huang, J. C. and Su, S. W., Mater. Trans. JIM, 1999, 40, 744

36. Taylor, G. I., J. Inst. Met., 1938, 62, 307.

37. McHargue, C. J., Jetter, L. K. and Ogle, J. C., Trans. AIME, 1959, 215, 233.

38. English, A. T. and Chin, G. Y., Acta metall., 1965, 13, 1013.

39. Hosford, W. F., The Mechanics of Crystals and Textured Polycrystals. Oxford University Press, Oxford, UK, 1993. 